\title{
Gait kinematic analysis in patients with a mild form of central cord syndrome
}

\author{
Angel Gil-Agudo ${ }^{1 *}$, Soraya Pérez-Nombela ${ }^{1}$, Arturo Forner-Cordero ${ }^{2}$, Enrique Pérez-Rizo ${ }^{1}$, Beatriz Crespo-Ruiz ${ }^{1}$, \\ Antonio del Ama-Espinosa ${ }^{1}$
}

\begin{abstract}
Background: Central cord syndrome (CCS) is considered the most common incomplete spinal cord injury (SCl). Independent ambulation was achieved in $87-97 \%$ in young patients with CCS but no gait analysis studies have been reported before in such pathology. The aim of this study was to analyze the gait characteristics of subjects with CCS and to compare the findings with a healthy age, sex and anthropomorphically matched control group (CG), walking both at a self-selected speed and at the same speed.
\end{abstract}

Methods: Twelve CCS patients and a CG of twenty subjects were analyzed. Kinematic data were obtained using a three-dimensional motion analysis system with two scanner units. The CG were asked to walk at two different speeds, at a self-selected speed and at a slower one, similar to the mean gait speed previously registered in the CCS patient group. Temporal, spatial variables and kinematic variables (maximum and minimum lower limb joint angles throughout the gait cycle in each plane, along with the gait cycle instants of occurrence and the joint range of motion - ROM) were compared between the two groups walking at similar speeds.

Results: The kinematic parameters were compared when both groups walked at a similar speed, given that there was a significant difference in the self-selected speeds $(p<0.05)$. Hip abduction and knee flexion at initial contact, as well as minimal knee flexion at stance, were larger in the CCS group $(p<0.05)$. However, the range of knee and ankle motion in the sagittal plane was greater in the CG group $(p<0.05)$. The maximal ankle plantar-flexion values in stance phase and at toe off were larger in the CG $(p<0.05)$.

Conclusions: The gait pattern of CCS patients showed a decrease of knee and ankle sagittal ROM during level walking and an increase in hip abduction to increase base of support. The findings of this study help to improve the understanding how CCS affects gait changes in the lower limbs.

\section{Background}

Incomplete spinal cord injury (SCI), comprising about $30 \%$ of cases, is the most frequent form of SCI [1]. The central cord syndrome (CCS) is considered the most common incomplete SCI syndrome with a reported incidence varying from $15.7 \%$ to $25 \%$ [2]. CCS was first described by Schneider as a condition that is associated with sacral sparing and it is characterized by motor weakness that affects more the upper extremities than the lower limbs [3]. Independent ambulation was achieved in

\footnotetext{
* Correspondence: amgila@sescam.jccm.es

${ }^{1}$ Biomechanics and Technical Aids Unit, Department of Physical Medicine and Rehabilitation, National Hospital for Spinal Cord Injury. SESCAM. Finca the Peraleda s/n, Toledo, 45071, Spain

Full list of author information is available at the end of the article
}

$87-97 \%$ in younger patients compared to $31-41 \%$ in patients older than 50 years at the time of injury [4].

The effect that the level of the lesion has on spasticty during walking has been studied in SCI patients [5], as have the changes in gait in patients with cervical myelopathy following therapeutic interventions [6], and even the gait of children and adolescents with SCI [7]. However, there are few studies that have focused on the biomechanics of gait in patients with CCS. To date, comparative biomechanical data has only been obtained in such patients for gait aided by one or two walking sticks [8]. However, the need to use biomechanical analyses to evaluate this patient group has been already emphasised $[7,9]$. The specific walking disorders occurring after incomplete SCI have been scarcely described

\section{Biomed Central}


in the literature. A recent study described the disturbances in the gait patterns of children and adolescents with SCI underscoring the importance of gait analysis as a tool to take therapeutic decisions, such as the prescription of orthosis or a surgical procedure, and to evaluate the patient during treatment or after surgical intervention [7].

Walking problems following CCS and other incomplete SCI syndromes have led to a wave of interest in using specific treatments, such as botulinum toxin type A [10] in combination with splinting to correct gait patterns. Different gait analyses have been carried out in several neuro-motor disorders $[6,11,12]$. These studies provide the basis to describe the type of gait disturbances that can be expected in these groups of patients and serve to define a rehabilitation therapy with realistic goals. In this context, the aim of the present study is to analyze the gait characteristics of subjects with CCS in order to quantify their gait pattern, and to compare these findings with a healthy age and sex matched control group using three-dimensional gait analysis walking at a self selected speed and at similar speed in both groups. The hypothesis tested was that kinematic values would in most cases be significantly different to those from a normal population, not only in the spatialtemporal parameters of gait but also in the joint motion. Accordingly, the findings obtained from the kinematic analysis of gait performed here should help to define the treatment necessary to resolve the problems detected.

\section{Methods}

\section{Subjects}

Twelve patients suffering from CCS participated in the experiments. Their average age was $42.6 \pm 17.3$ years (range, 21-61 years), height $162 \pm 0.1 \mathrm{~cm}$ (range, 146$186 \mathrm{~cm}$ ) and weight $68.7 \pm 15.6 \mathrm{~kg}$ (range, $40-89 \mathrm{~kg}$ : Table 1). The inclusion criteria were:

- Age range between 18 and 65 years.

- Clinical diagnosis of CCS: Patients with Spinal Cord Injury that displayed motor weakness affecting the upper limbs more than the lower limbs [3].

- Absence of previous history of locomotor or neurologic abnormality.

- Injury at least 12 months old.

The exclusion criteria were:

- Passive restriction of the joints.

- A diagnosis of any other neurological or orthopaedic disease that could affect locomotion.

Table 1 Clinical characteristics of both groups

\begin{tabular}{|c|c|c|}
\hline Variable & CCS group $(n=12)$ & Control group $(n=20)$ \\
\hline$\overline{S e x}(\operatorname{men})^{\dagger}$ & $8(67)$ & $12(60)$ \\
\hline Age (years)* & $42.58(17.3)$ & $34.50(9.8)$ \\
\hline Height $(\mathrm{cm})^{*}$ & $162(13.44)$ & $167(8.08)$ \\
\hline Weight $(\mathrm{kg}) *$ & $68.7(15.6)$ & $65.9(10.8)$ \\
\hline Time since injury (months)* & $16.2(15.7)$ & NA \\
\hline Age when injury (years)* & $40.5(16.4)$ & NA \\
\hline Level of injury $\mathrm{C}^{\dagger}$ & $1(8.3)$ & NA \\
\hline Level of injury $\mathrm{C}^{\dagger}$ & $5(41.6)$ & NA \\
\hline Level of injury $\mathrm{C} 5^{\dagger}$ & $2(16.6)$ & NA \\
\hline Level of injury $\mathrm{C}^{\dagger}$ & $2(16.6)$ & NA \\
\hline Level of injury $C 7^{\dagger}$ & $2(16.6)$ & NA \\
\hline Right upper limb motor score(maximum 25)* & $19.5(3.1)$ & 25 \\
\hline Left upper limb motor score (maximum 25)* & $19.6(3.5)$ & 25 \\
\hline Right lower limb motor score (maximum 25)* & $21.7(3.2)$ & 25 \\
\hline Left lower limb motor score (maximum 25)* & $21.4(3.9)$ & 25 \\
\hline Upper Limb Motor Score (maximum 50) & $33.83(4.41)$ & 50 \\
\hline Lower Limb Motor Score (maximum 50) & $42.33(5.19)$ & 50 \\
\hline Average between upper limb and lower limb motor score. & 8.50 & NA \\
\hline Ashworth score* & $1.21(0.2)$ & NA \\
\hline WISCI II & $20(100)$ & NA \\
\hline TUG (seconds)* & $17.1(6.9)$ & NA \\
\hline 10MWT (seconds)* & $17.4(6.7)$ & NA \\
\hline
\end{tabular}

${ }^{\dagger}$ Data are expressed as number (\%) for categorical variables.

*Data are expressed as mean (SD) for continuous variables. 
- A diagnosis of any other disease associated with memory, concentration and/or visual deficits.

- Failure to comply with any of the criteria for inclusion.

Data from CCS patients were compared to an age, sex and anthropomorphically-matched healthy control group (CG) that included 20 subjects (12 male and 8 female). Their average age was $34.5 \pm 9.8$ years (range, 22-65), height, $167 \pm 0.1 \mathrm{~cm}$ (range 157-184 cm) and weight 65.9 $\pm 10.8 \mathrm{~kg}$ (range $51-95 \mathrm{~kg}$ ). All the participants provided informed consent prior to be included in this study and the study design was approved by local ethics committee.

\section{Materials}

Kinematic data were recorded at $200 \mathrm{~Hz}$ using a threedimensional motion analysis system (CODA System.6, Charnwood Dynamics, Ltd, UK) with two scanner units. Eleven active markers were placed on each lower limb (Figures 1 and 2) following a model described previously [8]. The recording was obtained simultaneously from both sides.

\section{Data collection}

All CCS patients were asked to walk barefoot along a 10-m long walkway at a self-selected speed while

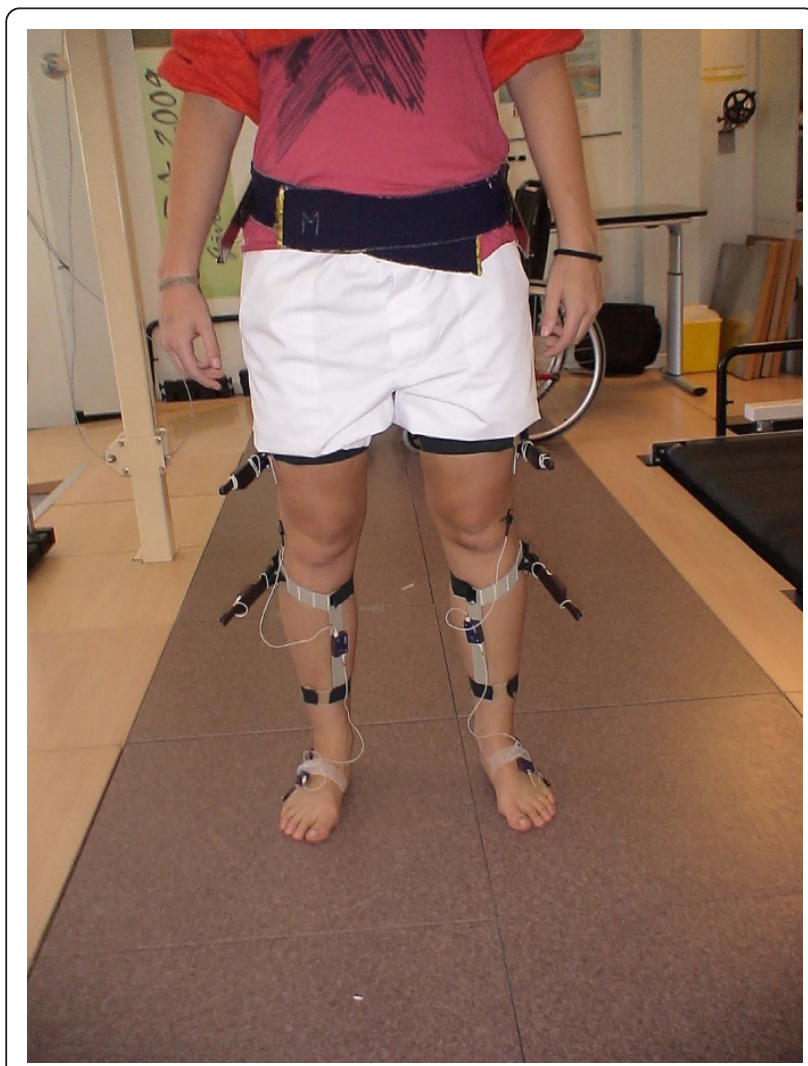

Figure 1 Marker placement in a subject. Frontal plane.

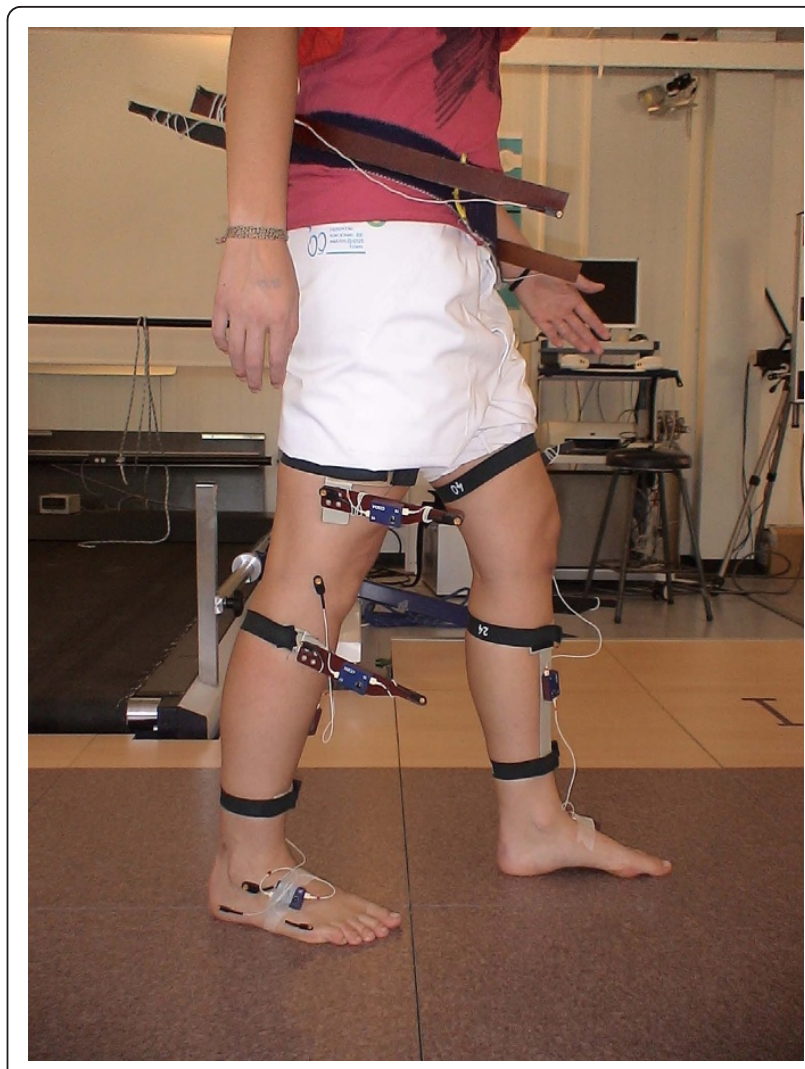

Figure 2 Marker placement in a subject. Sagital plane.

temporal-spatial and kinematic data were recorded. It must be noted that all the kinematic parameters of gait depend on the speed [13]. Therefore, the CG were asked to walk at two different speeds, at a self-selected speed and at a slower one that was similar to the mean gait speed registered previously in the CCS patient group. Considering that the average speed of the patients was $0.7 \mathrm{~m} / \mathrm{s}(\mathrm{SD}=0.2)$, the slow speed trials of the healthy controls were only included when the walking speed were between $0.7 \mathrm{~m} / \mathrm{s}$ and $1.2 \mathrm{~m} / \mathrm{s}$ [13]. The subjects in the control group were helped to walk more slowly with vocal commands.

Five valid trials were collected for each patient at a self selected speed and for CG at a self selected speed and at slow speed to reduce intrasubject variability. All the subjects were given a 1 -minute rest period between trials.

\section{Data analysis}

For each trial, a single gait cycle corresponding to the patient's cycle when crossing the midpoint of a $10-\mathrm{m}$ walkway was selected to ensure that the gait pattern was free of the influence of the initial acceleration and the final braking. The temporal-spatial variables registered were: gait velocity, stride length, step length, stride time, step time, strides/minute, steps/minute or cadence, and 
percentage of stance phase duration. The joint motion data included: maximum and minimum value of lower limb joint angles throughout the gait cycle in 3 planes, along with the gait cycle instants of occurrence and the joint range of motion (ROM). Both groups of variables were compared between the two groups, CCS and CG.

The data from right and left limbs were averaged. All temporal events were expressed as gait cycle percentages (0-100\%), defined between two consecutive heel-strikes of the same limb. The spatial parameters, speed, stride length, and step length were normalised by the subject height $[5,11]$.

\section{Statistical analysis}

For each subject, each computed parameter was calculated as the average of the values obtained in the five trials considered. A descriptive analysis was made of the clinical and functional variables by calculating the mean and standard deviation of the quantitative variables and the frequencies and percentages of the qualitative variables.

The normality distribution was checked for all the variables using the Kolmogorov-Smirnov test. Equality of variances was evaluated by Levene's test. Data were analysed using several one-way ANOVA tests (CCS group/ CG group) with $p=0.05$. All statistical analyses were performed using SPSS 12.0 (SPSS Inc, Chicago, IL, USA).

We certify that all applicable institutional and government regulations concerning the ethical use of human volunteers were followed during the course of this research.

\section{Results}

\section{Clinical measurements}

All patients had a cervical injury and they were classified as ASIA D [14]. The results of the clinical and functional assessment scales, such as Asworth score for spasticity measurement [15], WISCI (Walking Index Spinal Cord Injury) [16], TUG (Time Up and Go) [17] and 10MWT (10 Meter Walking Test) [17] most commonly used in this type of patient are shown in Table 1. The motor scores of both the upper limbs and lower limbs on both sides were similar, indicating symmetrical involvement [14], and the mean Ashworth score was $1.21 \pm 0.2$, which indicates that this group of patients does not suffer from pronounced spasticity [15]. None of the CCS patients needed a crutch to walk.

\section{Healthy control group at self selected speed versus patients with CCS}

Significant differences between both groups were obtained in all of the temporal-spatial parameters when walking at self-selected speed (Table 2). Given these differences and that speed affects the kinematic parameters, possibly acting as a confounding factor, a comparison was made with the kinematic data obtained when the control subjects walked at a speed similar to that of the CCS patients. In this way, we were sure that the differences observed in the kinematic parameters were not due to the speed of walking.

\section{Healthy control group and patients with CCS at a matched speed \\ a) Temporal-spatial parameters}

There were no significant differences in these parameters (Table 2).

\section{b) Pelvis motion}

Considering the average duration of the cycle, the maximal pelvic obliquity arose later in CCS patients than in controls, while the minimum obliquity occurred earlier in the patients. In addition, there was a slight anterior

Table 2 Temporal-spatial parameters between CCS group and control group

\begin{tabular}{|c|c|c|c|c|c|c|c|c|c|}
\hline \multirow[b]{2}{*}{ Variable } & \multicolumn{3}{|c|}{ CCS group $(n=12)$} & \multicolumn{2}{|c|}{$\begin{array}{l}\text { Control group (self-selected speed) } \\
\qquad(\mathrm{n}=20)\end{array}$} & \multicolumn{4}{|c|}{$\begin{array}{l}\text { Control group (slow speed) } \\
\qquad(\mathrm{n}=20)\end{array}$} \\
\hline & Units & Mean & DS & Mean & DS & $P$ value & Mean & DS & $P$ value \\
\hline Speed & $\mathrm{m} / \mathrm{s}$ & 0.72 & \pm 0.25 & 1.28 & \pm 0.11 & 0.000 & 0.71 & \pm 0.08 & 0.835 \\
\hline Speed $^{*}$ & \%height & 43.22 & \pm 15.09 & 76.79 & \pm 8.66 & 0.000 & 42.10 & \pm 4.45 & 0.806 \\
\hline Stride Length* & \%height & 58.20 & \pm 11.67 & 80.24 & \pm 4.26 & 0.000 & 61.62 & \pm 4.35 & 0.345 \\
\hline Stride Time & s & 1.44 & \pm 0.32 & 1.06 & \pm 0.08 & 0.002 & 1.48 & \pm 0.15 & 0.685 \\
\hline Strides/Minute & & 43.37 & \pm 8.31 & 57.28 & \pm 4.48 & 0.000 & 40.98 & \pm 3.69 & 0.363 \\
\hline Step Length* & \%height & 29.38 & \pm 6.35 & 40.38 & \pm 2.23 & 0.000 & 30.64 & \pm 2.20 & 0.519 \\
\hline Step Time & s & 0.72 & \pm 0.16 & 0.53 & \pm 0.04 & 0.002 & 0.74 & \pm 0.07 & 0.726 \\
\hline Cadence & Steps/Minute & 87.09 & \pm 16.26 & 114.22 & \pm 9.21 & 0.000 & 82.57 & \pm 7.44 & 0.380 \\
\hline Single Support & \%cycle & 0.44 & \pm 0.05 & 0.38 & \pm 0.02 & 0.000 & 0.45 & \pm 0.04 & 0.494 \\
\hline Double Support & \%cycle & 0.27 & \pm 0.13 & 0.15 & \pm 0.02 & 0.006 & 0.28 & \pm 0.05 & 0.874 \\
\hline Percentage stance & \%cycle & 68.41 & \pm 4.58 & 63.99 & \pm 1.19 & 0.007 & 69.20 & \pm 1.81 & 0.573 \\
\hline
\end{tabular}

Significant difference between conditions at $\mathrm{P}<0.05$.

*Height-corrected values. 
pelvic rotation in the CCS patients that was advanced in the gait cycle (Table 3).

\section{c) Hip motion}

The maximal hip flexion during stance was significantly delayed in the group of CCS patients with respect to the control group (Figure 3a) and these differences were larger in the frontal plane (Table 4). At initial contact, the patients showed larger hip abduction, which reversed during the course of the stance phase as at toe-off, the control subjects showed larger hip abduction. Indeed, the CG subjects also had a larger hip abduction during swing (Table 4).

The maximal hip adduction during stance occurred earlier in the CG, while during swing the maximal hip adduction was delayed in the CG (Figure 3b). In fact, the maximal hip abduction values during stance were considerably delayed in the CG (Table 4).

\section{d) Knee kinematics}

The knee flexion at the initial contact was significantly greater in the patients although the maximal flexion during the stance phase was larger in the CG. However, the minimal knee flexion during swing and stance were larger in the CCS group, while knee flexion at toe off was lower in CCS. It must be noted that the CG reached a greater flexion during swing and they showed higher knee ROM in the sagittal plane (Table 5). In addition, the minimal knee flexion during swing was reached earlier in the CG (Figure 3c).

\section{e) Ankle kinematics}

The minimal dorsi-flexion or maximal ankle plantarflexion during stance, at toe-off and during the swing phase was smaller in the CCS group. Consequently, the ankle flexo-extension ROM was higher in the CG.

The maximal value of the ankle plantar-flexion occurred earlier in the CCS patients during stance but not during swing (Figure 3d). Likewise, the instant of minimal supination occurred earlier in the CCS group (Table 6). However, the prono-supination ROM and the maximal supination values were higher in the CG.

\section{Discussion}

The aim of this study was to objectively and quantitatively analyze and evaluate the gait of patients with CCS using three-dimensional kinematic movement analysis equipment, and to compare them with healthy subjects. This comparison was made at both a self-selected speed and at a matched speed in order to avoid any variation due to velocity. The main findings of this study should serve to define the basic rehabilitation strategies for CCS patients.

The results of our study reveal that not only do patients with CCS walk at a slower speed but also, that they display a series of kinematic alterations such as a smaller range of movement in the sagittal plane of the knee, greater abduction of the hip at the initial contact and during the oscillation phase, as well as a diminished range of joint movement in the ankle.

Some of these kinematic findings coincide with the data published elsewhere regarding the gait of patients with incomplete SCI $[18,19]$, such as the limited flexion of the knee during the oscillation phase. Previously, the

Table 3 Pelvic kinematic parameters

\begin{tabular}{|c|c|c|c|c|c|c|}
\hline \multirow[b]{2}{*}{ Variable } & \multicolumn{3}{|c|}{ CCS group $(n=12)$} & \multicolumn{2}{|c|}{ Control Group (slow speed) $(n=20)$} & \multirow[b]{2}{*}{$P$ value } \\
\hline & Units & Mean & SD & Mean & SD & \\
\hline \multicolumn{7}{|l|}{ PELVIS TILT } \\
\hline Maximum & degrees & 20.26 & \pm 8.09 & 20.46 & \pm 4.39 & 0.939 \\
\hline Minimum & degrees & 13.66 & \pm 7.371 & 15.14 & \pm 4.87 & 0.544 \\
\hline Range of motion & degrees & 6.60 & \pm 2.48 & 5.32 & \pm 1.44 & 0.123 \\
\hline Time at max. pelvis tilt & $\%$ cycle & 48.17 & \pm 10.50 & 38.52 & \pm 16.20 & 0.076 \\
\hline Time at min. pelvis tilt & $\%$ cycle & 48.50 & \pm 12.32 & 57.16 & \pm 14.02 & 0.088 \\
\hline \multicolumn{7}{|l|}{ PELVIS OBLIQUITY } \\
\hline Maximum & degrees & 3.31 & \pm 1.62 & 3.79 & \pm 1.29 & 0.363 \\
\hline Minimum & degrees & -3.44 & \pm 1.64 & -4.13 & \pm 1.31 & 0.200 \\
\hline Range of motion & degrees & 6.75 & \pm 3.19 & 7.92 & \pm 2.56 & 0.265 \\
\hline Time at max. pelvis obliquity & $\%$ cycle & 43.84 & \pm 23.85 & 26.79 & \pm 10.92 & 0.010 \\
\hline Time at min. pelvis obliquity & $\%$ cycle & 51.91 & \pm 14.31 & 65.44 & \pm 16.05 & 0.023 \\
\hline \multicolumn{7}{|l|}{ PELVIS ROTATION } \\
\hline Maximum & degrees & 5.75 & \pm 2.07 & 4.66 & \pm 1.18 & 0.067 \\
\hline Minimum & degrees & -6.00 & \pm 2.49 & -4.64 & \pm 1.28 & 0.050 \\
\hline Range of motion & degrees & 11.74 & \pm 4.47 & 9.30 & \pm 2.28 & 0.049 \\
\hline Time at max. pelvis rotation & \% cycle & 29.74 & \pm 7.38 & 36.09 & \pm 5.71 & 0.011 \\
\hline Time at min. pelvis rotation & $\%$ cycle & 64.98 & \pm 14.82 & 66.87 & \pm 13.72 & 0.716 \\
\hline
\end{tabular}

Significant difference between conditions at $\mathrm{P}<0.05$. 

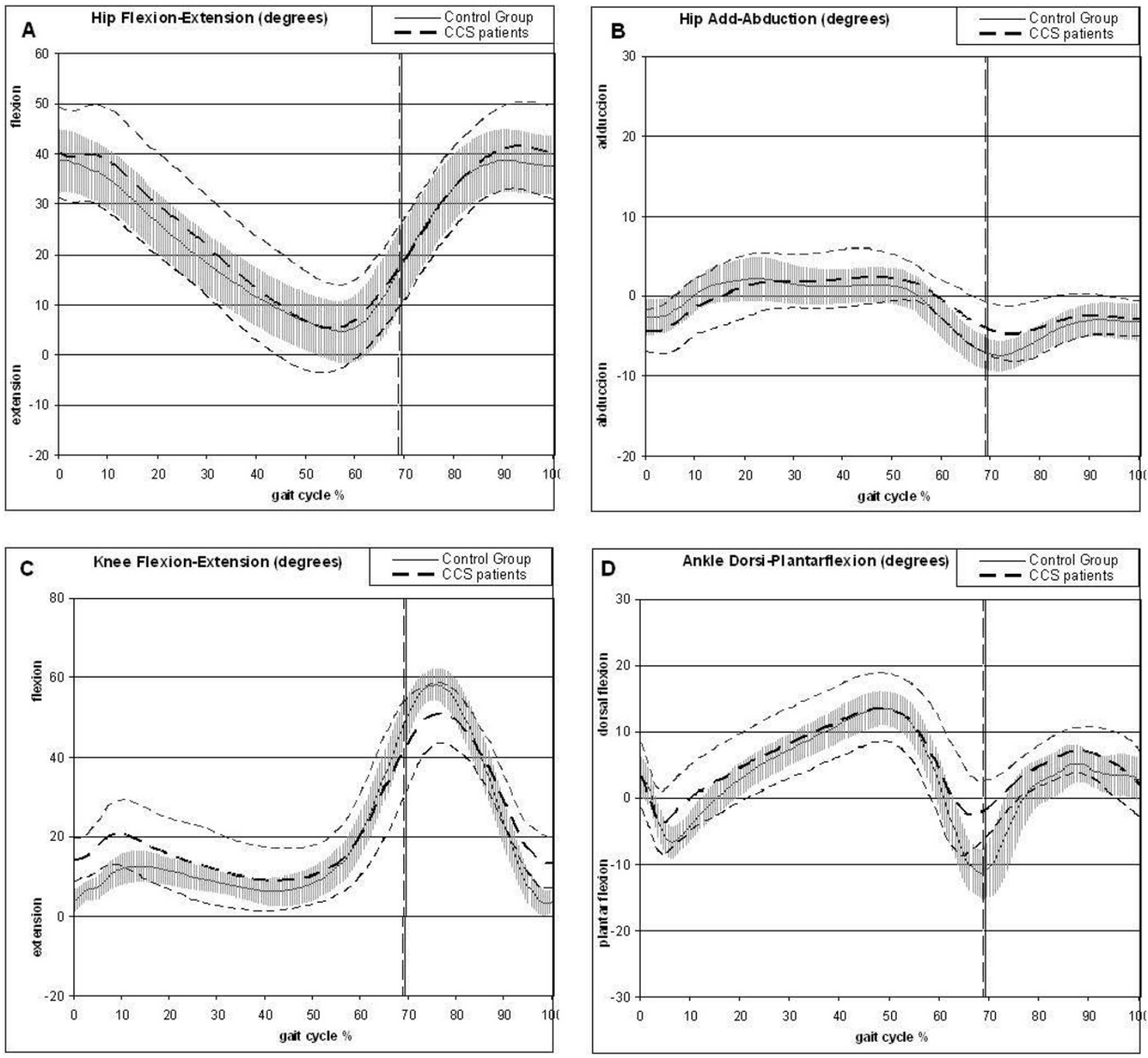

Figure 3 Mean kinematic features of CCS patients (dashed line, mean and standard deviation) compared with the control group (continue thick line and grey line with standard deviation). The $X$-axis reflects the percentage of the gait cycle and on the $Y$-axis the units are in degrees. Kinematic curve for hip flexion-extension (A), hip adduction-abduction (B), knee flexion-extension (C) and the ankle dorsi-plantar flexion (D).

limited flexion of the knee during the oscillation phase was explained by the antagonistic action of the rectus femoris muscle and of the Vastus lateralis [18], leading to the recommendation that strategies are adopted to stretch these muscles or other such adaptations of clinical treatments to improve these patients' capacity to walk. This limited flexion in our group of patients was also evident, although we cannot confirm that it is due to the antagonistic action of the quadriceps since we did not register the electromyographic activity.
In our patients, the range of knee movement was diminished in the sagittal plane, whereby the knee was more flexed during the support phase and less flexed than in the control group during the oscillation phase. This reduced range of knee flexion has been observed in other studies of patients with paraplegic-spastic gait of diverse aetiology, in which this limitation was proposed to be correlated with the degree of spasticity [5]. The degree of spasticity is mild in our sample of patients, and they suffer no passive limitation to the 
Table 4 Hip kinematic parameters

\begin{tabular}{|c|c|c|c|c|c|c|}
\hline \multirow[b]{2}{*}{ Variable } & \multicolumn{3}{|c|}{ CCS group $(n=12)$} & \multicolumn{2}{|c|}{ Control Group (slow speed) $(n=20)$} & \multirow[b]{2}{*}{$P$ value } \\
\hline & Units & Mean & SD & Mean & SD & \\
\hline \multicolumn{7}{|l|}{ HIP FLEXION-EXTENSION } \\
\hline Flexion at initial contact & degrees & 40.20 & \pm 9.11 & 38.68 & \pm 6.41 & 0.584 \\
\hline Max. flex. in stance phase & degrees & 41.24 & \pm 9.61 & 39.00 & \pm 6.28 & 0.430 \\
\hline Min. flex. in stance phase & degrees & 4.14 & \pm 8.69 & 4.15 & \pm 6.41 & 0.998 \\
\hline Flexion at toe off & degrees & 17.60 & \pm 10.17 & 17.92 & \pm 6.39 & 0.913 \\
\hline Max. flex. in swing phase & degrees & 42.70 & \pm 8.79 & 39.45 & \pm 6.20 & 0.229 \\
\hline Min. flex. in swing phase & degrees & 17.45 & \pm 9.96 & 17.92 & \pm 6.39 & 0.870 \\
\hline Range of motion & degrees & 39.39 & \pm 6.27 & 36.26 & \pm 4.18 & 0.099 \\
\hline Time at max. flex. in stance phase & $\%$ cycle & 4.57 & \pm 3.71 & 1.53 & \pm 1.65 & 0.003 \\
\hline Time at min. flex. in stance phase & $\%$ cycle & 55.48 & \pm 2.82 & 57.17 & \pm 1.74 & 0.044 \\
\hline Time at flexion toe off & $\%$ cycle & 68.41 & \pm 4.58 & 69.20 & \pm 1.81 & 0.573 \\
\hline Time at max. flex. in swing phase & $\%$ cycle & 93.03 & \pm 2.71 & 92.90 & \pm 3.32 & 0.911 \\
\hline Time at min. flex. in swing phase & $\%$ cycle & 68.84 & \pm 5.11 & 69.21 & \pm 1.81 & 0.813 \\
\hline \multicolumn{7}{|l|}{ HIP ADDUCTIO-ABDUCTION } \\
\hline Abd. at initial contact & degrees & 4.44 & \pm 2.61 & 2.56 & \pm 2.30 & 0.041 \\
\hline Max. add. in stance phase & degrees & 3.99 & \pm 2.69 & 3.30 & \pm 2.32 & 0.451 \\
\hline Max. abd in stance phase & degrees & 6.83 & \pm 2.77 & 7.63 & \pm 1.92 & 0.339 \\
\hline Adduction at toe off & degrees & -4.36 & \pm 3.61 & -7.44 & \pm 2.05 & 0.016 \\
\hline Max. add in swing phase & degrees & -0.57 & \pm 2.54 & -2.33 & \pm 2.12 & 0.044 \\
\hline Max. abd in swing phase & degrees & 6.34 & \pm 2.84 & 7.99 & \pm 1.99 & 0.063 \\
\hline Range of motion & degrees & 12.20 & \pm 3.25 & 11.42 & \pm 2.68 & 0.471 \\
\hline Time at max. add in stance phase & $\%$ cycle & 41.94 & \pm 11.35 & 30.26 & \pm 11.97 & 0.011 \\
\hline Time at max. abd in stance phase & $\%$ cycle & 35.06 & \pm 28.94 & 62.48 & \pm 10.44 & 0.008 \\
\hline Time at max. add in swing phase & $\%$ cycle & 85.30 & \pm 10.23 & 92.34 & \pm 4.04 & 0.040 \\
\hline Time at max. abd in swing phase & $\%$ cycle & 80.28 & \pm 7.85 & 72.36 & \pm 4.26 & 0.006 \\
\hline \multicolumn{7}{|l|}{ HIP ROTATION } \\
\hline Maximum Internal rotation & degrees & 1.29 & \pm 6.16 & -0.486 & \pm 6.59 & 0.455 \\
\hline Minimum internal rotation & degrees & -12.17 & \pm 8.13 & -12.58 & \pm 6.83 & 0.880 \\
\hline Range of motion & degrees & 13.47 & \pm 4.63 & 12.09 & \pm 2.19 & 0.264 \\
\hline Time at max. internal rotation & $\%$ cycle & 51.03 & \pm 14.98 & 49.77 & \pm 25.03 & 0.859 \\
\hline Time at min. internal rotation & $\%$ cycle & 53.77 & \pm 26.00 & 59.82 & \pm 17.19 & 0.483 \\
\hline
\end{tabular}

Significant difference between conditions at $\mathrm{P}<0.05$.

joint movement. Accordingly, this alteration might be due to a specific loss muscle control, as suggested previously[20].

The reduced joint movement of the knee and ankle in the sagittal plane is not accompanied by a reduction in the hip, as seen elsewhere [6]. The normal peak of plantar flexion of the ankle is also diminished in patients with CCS and as occurs in other neurological disorders, this contributes to the reduced walking speed [21].

From a clinical point of view, the data obtained suggest that in patients with CCS, we should preferentially work on lengthening the ischiotibialis muscles and on muscle coordination to try to reduce the knee flexion at initial contact, and not only on strengthening the muscles. Indeed, while some studies indicate that an increase in strength in the lower limbs is related with an improvement in gait [22], others consider that this is not always the case [23].

Likewise, we also recommend stretching the anterior rectus femoris and the Vastus lateralis to help increase knee flexion during the oscillation phase and in general, to improve the range of knee mobility in the sagittal plane [18].

One issue that cannot be overlooked is the walking speed. It has been demonstrated that the speed at which we walk conditions the kinematic variables of our gait [13]. Our patients walk at a slower speed than the control group when walking at the self-selected speed, with shorter strides and a lower cadence, while the double support phase was longer. It has been reported that decreasing gait speed might be useful to prevent a fall when gait is perturbed $[24,25]$. 
Table 5 Knee kinematic parameters

\begin{tabular}{|c|c|c|c|c|c|c|}
\hline \multirow[b]{2}{*}{ Variable } & \multicolumn{3}{|c|}{ CCS group $(n=12)$} & \multicolumn{2}{|c|}{ Control Group (slow speed) $(n=20)$} & \multirow[b]{2}{*}{$P$ value } \\
\hline & Units & Mean & SD & Mean & SD & \\
\hline \multicolumn{7}{|l|}{ KNEE FLEXION } \\
\hline Flexion at initial contact & degrees & 14.20 & \pm 5.50 & 4.03 & \pm 3.02 & 0.000 \\
\hline Max. flex. in stance phase & degrees & 43.33 & \pm 8.91 & 48.72 & \pm 3.94 & 0.025 \\
\hline Min. flex. in stance phase & degrees & 6.72 & \pm 6.60 & 2.87 & \pm 3.21 & 0.034 \\
\hline Flexion at toe off & degrees & 44.25 & \pm 8.94 & 49.73 & \pm 3.92 & 0.023 \\
\hline Max. flex. in swing phase & degrees & 53.53 & \pm 7.65 & 59.19 & \pm 3.76 & 0,009 \\
\hline Min. flex. in swing phase & degrees & 12.67 & \pm 6.37 & 2.89 & \pm 3.44 & 0.000 \\
\hline Range of motion & degrees & 47.51 & \pm 9.98 & 57.39 & \pm 4.37 & 0.001 \\
\hline Time at max. flex. in stance phase & $\%$ cycle & 67.33 & \pm 6.30 & 68.86 & \pm 1.83 & 0.313 \\
\hline Time at min. flex. in stance phase & $\%$ cycle & 30.38 & \pm 12.53 & 13.65 & \pm 12.76 & 0.001 \\
\hline Time at max. flex. in swing phase & $\%$ cycle & 74.65 & \pm 3.15 & 75.26 & \pm 1.59 & 0.476 \\
\hline Time at min. flex. in swing phase & $\%$ cycle & 98.76 & \pm 0.85 & 98.56 & \pm 1.10 & 0.601 \\
\hline \multicolumn{7}{|l|}{ KNEE VARUS } \\
\hline Maximum & degrees & 3.69 & \pm 3.62 & 5.06 & \pm 2.38 & 0.204 \\
\hline Minimum & degrees & -6.43 & \pm 6.68 & -7.03 & \pm 4.20 & 0.757 \\
\hline Range of motion & degrees & 10.13 & \pm 4.18 & 12.10 & \pm 3.98 & 0.193 \\
\hline Time at max. varus & degrees & 59.92 & \pm 20.06 & 54.16 & \pm 19.61 & 0.431 \\
\hline Time at min. varus & degrees & 56.91 & \pm 18.76 & 70.17 & \pm 9.22 & 0.012 \\
\hline \multicolumn{7}{|l|}{ KNEE ROTATION } \\
\hline Maximum internal rotation & degrees & 5.02 & \pm 5.79 & 4.47 & \pm 7.75 & 0.834 \\
\hline Minimum internal rotation & degrees & -8.56 & \pm 5.22 & -9.52 & \pm 7.42 & 0.698 \\
\hline Range of motion & degrees & 13.58 & \pm 2.83 & 13.99 & \pm 2.77 & 0.690 \\
\hline Time at max. internal rotation & $\%$ cycle & 43.96 & \pm 20.79 & 43.57 & \pm 21.15 & 0.960 \\
\hline Time at min. internal rotation & $\%$ cycle & 72.64 & \pm 13.10 & 73.85 & \pm 13.87 & 0.808 \\
\hline
\end{tabular}

Significant difference between conditions at $\mathrm{P}<0.05$.

Table 6 Ankle kinematic parameters

\begin{tabular}{|c|c|c|c|c|c|c|}
\hline \multirow[b]{2}{*}{ Variable } & \multicolumn{3}{|c|}{ CCS group $(n=12)$} & \multicolumn{2}{|c|}{ Control Group (slow speed) $(n=20$} & \multirow[b]{2}{*}{$P$ value } \\
\hline & Units & Mean & SD & Mean & SD & \\
\hline \multicolumn{7}{|l|}{ ANKLE DORSIFLEXION } \\
\hline Dorsiflexion at initial contact & degrees & 3.29 & \pm 4.90 & 3.13 & \pm 3.15 & 0.912 \\
\hline Max. dorsi. in stance phase & degrees & 15.07 & \pm 5.00 & 14.36 & \pm 2.62 & 0.600 \\
\hline Min. dorsi. in stance phase & degrees & -7.91 & \pm 4.98 & -13.84 & \pm 3.66 & 0.001 \\
\hline Dorsiflexion at toe off & degrees & -4.05 & \pm 5.99 & -12.98 & \pm 4.14 & 0.000 \\
\hline Max. dorsi. In swing phase & degrees & 8.97 & \pm 3.75 & 6.72 & \pm 2.72 & 0.059 \\
\hline Min. dorsi. In swing phase & degrees & -4.99 & \pm 5.67 & -13.15 & \pm 4.21 & 0.000 \\
\hline Range of motion & degrees & 23.52 & \pm 6.10 & 28.50 & \pm 3.58 & 0.007 \\
\hline Time at max. dorsi. in stance phase & $\%$ cycle & 47.98 & \pm 5.13 & 48.44 & \pm 2.97 & 0.749 \\
\hline Time at min. dorsi. in stance phase & $\%$ cycle & 36.18 & \pm 20.75 & 62.63 & \pm 13.97 & 0.000 \\
\hline Time at max. dorsi. in swing phase & $\%$ cycle & 87.54 & \pm 3.36 & 89.20 & \pm 4.34 & 0.265 \\
\hline Time at min. dorsi. in swing phase & $\%$ cycle & 74.68 & \pm 10.09 & 69.43 & \pm 1.86 & 0.029 \\
\hline \multicolumn{7}{|l|}{ ANKLE SUPINATION } \\
\hline Maximum & degrees & 8.94 & \pm 9.77 & 15.55 & \pm 5.42 & 0.019 \\
\hline Minimum & degrees & -15.59 & \pm 7.79 & -16.75 & \pm 11.68 & 0.761 \\
\hline Range of motion & degrees & 24.53 & \pm 6.16 & 32.30 & \pm 11.66 & 0.041 \\
\hline Time at max. supination & degrees & 68.07 & \pm 10.83 & 54.86 & \pm 21.26 & 0.055 \\
\hline Time at min. supination & degrees & 52.00 & \pm 16.47 & 63.57 & \pm 11.64 & 0.027 \\
\hline
\end{tabular}

Significant difference between conditions at $\mathrm{P}<0.05$. 
These findings agree with earlier studies of patients with different neurological diseases such as patients with spastic paraplegia [26], cervical myelopathy [6] or Duchenne's muscular dystrophy [11]. For this reason, the subjects in the control group were also made to walk at a similar speed as the group of patients with CCS. For the control subjects to walk more slowly, they reduced the length of their stride and their cadence, and they increased the duration of the support phase, as demonstrated in previous studies [13]. In this way, we ensured that the speed did not influence the kinematic variables, although we must also bear in mind that this may introduce a certain bias in the data from the control group since walking slowly may modify their normal gait.

Since there are many parameters that can be obtained from gait analysis, it is necessary to take into account the reliability of measurements in different joint planes. In marker based gait analysis, some of these parameters can be obtained with greater precision (hip and knee ROM in the sagittal plane) than others (such as hip or knee rotation), since a larger movement is measured.

There are certain limitations associated with this study, the principal one being the lack of kinetic and electromyographic data. Since we are aware of the importance of such data, we have now introduced the necessary modifications to our equipment so that these parameters can be incorporated in future studies. Despite this limitation, the data regarding gait has been collected from the largest group of CCS patients yet studied. To date, the only study of CCS patients published using a three-dimensional analysis of movement to evaluate the kinematics of gait did not describe the pattern obtained in these patients but rather, it compared these CCS patients walking with the aid of one or two walking sticks to evaluate the improvement in this population [8]. Thus, there was no attempt to describe the kinematic differences with respect to a control group of subjects. Hence, we consider that our data represents the first attempt to define the alterations in joint movement associated with this type of disorder, which should help improve the strategies adopted in rehabilitation therapies.

We believe it is difficult to perform studies on this type of population given that there is still no clear consensus regarding the diagnostic criteria. However, a recent review concluded [27] established that the existence of a difference of at least 10 points between the motor index of upper and lower limbs served as a good diagnostic criterion for CCS [27]. In our cohort, the mean difference in the motor index of upper and lower limbs was 8.5 points. Although we are aware that this does not reach the minimum threshold of 10 points, the difference is small and as such, the results presented here are likely to be relevant. Nevertheless, the small difference in the motor index found leads us to assume that our group of patients suffer a mild form of CCS.

\section{Conclusion}

CCS patients experience a decrease of knee and ankle sagittal motion during level walking and an increase of hip abduction. The reduction in the range of motion of these joints cannot be attributed to increased spasticity but rather to other compensatory mechanisms aimed at improving gait stability, and to the neural damage suffered by the patients.

The findings of this study help to improve the understanding how CCS affects gait changes in the lower limbs and how to design rehabilitation strategies for their treatment.

\section{Consent statement}

Written informed consent was obtained from the patient for publication of this research and accompanying images. A copy of the written consent is available for review by the Editor-in chief of this journal.

\section{Acknowledgements}

This work was supported by the Fondo of Investigaciones Sanitarias del Instituto of Salud Carlos III del Ministerio of Sanidad PI070352 (Spain), and cofunded by FEDER, Consejería of Sanidad of the Junta of Comunidades of Castilla-La Mancha (Spain) and FISCAM PI 2006/44 (Spain).

The authors thank Dr. Antonio Sánchez-Ramos (Head of Department of Physical Medicine and Rehabilitation) for facilitating our work. We would like to thank José Luis Rodríguez-Martín for his critical review of the manuscript and his recommendations regarding the methodology.

\section{Author details}

${ }^{1}$ Biomechanics and Technical Aids Unit, Department of Physical Medicine and Rehabilitation, National Hospital for Spinal Cord Injury. SESCAM. Finca the Peraleda s/n, Toledo, 45071, Spain. ²Biomechatronics Laboratory, Mechatronics Department, Polytechnic School of the University of São Paulo, Brazil.

\section{Authors' contributions}

AGA contributed to the concept and design, planning of study, analysis and interpretation of the data, drafting and completion of the manuscript. AFC contributed to design, analysis, completion of the manuscript and analysis of the data. EPR contributed to the concept, software development, design and acquisition of the data. SPN contributed to the analysis and acquisition of the data. BCR contributed to the analysis and acquisition of the data. AAE contributed to the software development, analysis and acquisition of the data. All authors read and approved the manuscript to be published.

\section{Competing interests}

None of the authors of this paper have any conflict of interest in relation to any sources of any kind pertinent to this study. No commercial party having a direct financial interest in the results of the research supporting this article has or will confer a benefit upon the author(s) or upon any organization with which the author(s) is/are associated.

Received: 18 January 2010 Accepted: 2 February 2011 Published: 2 February 2011 


\section{References}

1. Go BK, of Vivo MJ, Richards JS: The epidemiology of spinal cord injury. In Spinal cord injury: clinical outcomes from the model systems. Edited by: Stover SL, DeLisa JA, Whiteneck GG. Gaithersburg (MD): Aspen Publishing; 1995:21-55.

2. McKinley W, Santos K, Meade M, Brooke K: Incidence and outcomes of spinal cord injury clinical syndromes. J Spinal Cord Med 2007, 30(3):215-224.

3. Schneider RC, Cerry G, Pantek H: The syndrome of acute central cervical spinal cord injury; with special reference to the mechanisms involved in hyperextension injuries of cervical spine. J Neurosurg 1954, 11(6):546-577.

4. Newey ML, Sen PK, Fraser RD: The long-term outcome after central cord syndrome: a study of the natural. J Bone Joint Surg 2000, 82:851-855.

5. Krawetz P, Nance P: Gait analysis of spinal cord injured subjects: Effects of injury level and spasticity. Arch Phys Med Rehabil 1996, 77(7):635-638.

6. Kuhtz-Buschbeck JP, Jöhnk K, Mäder S, Stolze H, Mehdorn M: Analysis of gait in cervical myelopathy. Gait \& Posture 1999, 9:184-189.

7. Smith PA, Hasani S, Reiners K, Vogel LC, Harris GF: Gait analysis in children and adolescents with spinal cord injuries. J Spinal Cord Med 2004, 27: S44-S49.

8. Gil-Agudo A, Pérez-Rizo E, Del Ama-Espinosa A, Crespo-Ruiz B, PérezNombela S, Sánchez-Ramos A: Comparative biomechanical gait analysis of patients with central cord syndrome walking with one and two crutches. Clin Biomech (Bristol Avon) 2009, 24:551-557.

9. Patrick JH: The case for gait analysis as part of the management of incomplete spinal cord injury. Spinal Cord 2003, 41:479-482.

10. Al-Khodairy AT, Gobelet C, Rossier AB: Has botulinum toxin type A a place in the treatment of spasticity in spinal cord injury patients? Spinal Cord 1998, 36:854-858.

11. D'Angelo MG, Berti M, Piccinini L, Romei M, Guglieri M, Bonato $S$, Degrate A, Turconi AC, Bresolin N: Gait pattern in Duchenne muscular dystrophy. Gait \& Posture 2009, 29:36-41.

12. Galli M, Rigoldi C, Brunner R, Virji-Babul N, Giorgo A: Joint stiffness and gait pattern evaluation in children with Down syndrome. Gait \& Posture 2008, 28:502-506.

13. Ochi F, Esquenazi A, Hirai B, Talaty M: Temporal-Spatial Features of Gait after Traumatic Brain Injury. J. Head Trauma Rehabil 1999, 14(2):105-115.

14. Marino RJ, Barros T, Biering-Sorensen F, Burns SP, Donovan WH, Graves DE, Haak M, Hudson LM, Priebe MM, ASIA Neurological Standards Committee 2002: International standards for neurological classification of spinal cord injury. J Spinal Cord Med 2003, 26(Suppl 1):S50-S56.

15. Ashworth B: Preliminary trial of carisoprodal in multiple sclerosis. Practitioner 1964, 192:540-542.

16. Ditunno PI, Dittuno JF: Walking index for spinal cord injury (WISCI II): scale revision. Spinal Cord 2001, 39:654-656.

17. Van Hedel HJ, Markus W, Dietz V: Assessing walking ability in subjects with spinal cord injury: validity and reliability of 3 walking tests. Arch Phys Med Rehabil 2005, 86:190-196.

18. Ditunno J, Scivoletto G: Clinical relevance of gait research applied to clinical trials in spinal cord injury. Brain Res Bull 2009, 78(1):35-42.

19. van der Salm A, Nene AV, Maxwell DJ, Veltink PH, Hermens HJ, IJzerman MJ: Gait impairments in a group of patients with incomplete spinal cord injury and their relevance regarding therapeutic approaches using functional electrical stimulation. Artif Organs 2005, 29(1):8-14.

20. Alexeeva N, Broton JG, Suys S, Calancie B: Central cord syndrome of cervical spinal cord injury: widespread changes in muscle recruitment studied by voluntary contractions and transcranial magnetic stimulation. Exp Neurol 1997, 148(2):399-406.

21. Nadeau S, Gravel D, Arsenault AB, Bourbonnais D: Plantarflexor weakness as a limiting factor of gait speed in stroke subjects and the compensating role of hip flexors. Clin Biomech (Bristol, Avon) 1999, 14(2):125-35.

22. Kim CM, Eng JJ: Magnitude and pattern of 3D kinematic and kinetic gait profiles in persons with stroke: a relationship to walking speed. Gait Posture 2004, 20:140-146.

23. Wirz M, van Hedel HJ, Rupp R, Curt A, Dietz V: Muscle force and gait performance: relationship after spinal cord injury. Arch Phys Med Rehabil 2006, 87(9):1218-1822.

24. van den Bogert AJ, Pavol MJ, Grabiner MD: Response time is more important than walking speed for the ability of older adults to avoid a fall after a trip. J Biomech 2002, 35(2):199-20.
25. Forner Cordero A, Koopman HJ, van der Helm FC: Mechanical model of the recovery from stumbling. Biol Cybern 2004, 91(4):212-20.

26. Conrad B, Benecke R, Meinck HM: Gait disturbances in paraspastic patiens In: Delwaide PJ, Young RR, editors. Clinical Neurophysiology in Spasticity. Amsterdam: Elviser 1995, 155-174.

27. Pouw MH, van Middendorp JJ, van Kampen A, Hirschfeld S, Veth RP, EM-SC study, Curt A, Hosman AJ, van de Meent H: Diagnostic criteria of traumatic central cord syndrome. Part 1: A systematic review of clinical descriptors and scores. Spinal Cord 2010, 48(9):652-6.

doi:10.1186/1743-0003-8-7

Cite this article as: Gil-Agudo et al:: Gait kinematic analysis in patients with a mild form of central cord syndrome. Journal of NeuroEngineering and Rehabilitation 2011 8:7.

\section{Submit your next manuscript to BioMed Central and take full advantage of:}

- Convenient online submission

- Thorough peer review

- No space constraints or color figure charges

- Immediate publication on acceptance

- Inclusion in PubMed, CAS, Scopus and Google Scholar

- Research which is freely available for redistribution

Submit your manuscript at www biomedcentral com/submit
Ciomed Central 